the screws have been made extra deep. With the above inhaler I find it easy to administer all the ordinary anæsthetics, including ethyl chloride, and after removing the bag mixtures of chloroform and ether or chloroform alone. To use a different apparatus for each variety of anæsthetic is inconvenient and it is a great advantage to have an inhaler which can be properly cleaned and which is at any time available for the administration of all the ordinary anæsthetics.

O. HAMILTON WHITEFORD,

Plymouth. Senior Honorary Anesthetist, South Devon Hospital.

\section{A NEW RECTAL DILATOR.}

THE accompanying illustrations show a new form of rectal dilator made on the same principle as Hegar's wellknown uterine dilators. This set of dilators has been made for me by the Holborn Surgical Instrument Company, of 16. Thavies Inn, Holborn Circus, London, E.C., from whom the set of dilators can be obtained. They have the great advantage over any form of mechanical rectal dilator that no damage to the mucous membrane of the rectum can result from their use. They dilate perfectly gradually and smoothly and no force is required in using them. They are very much better than dilating bougies as being made

FIG. 1.

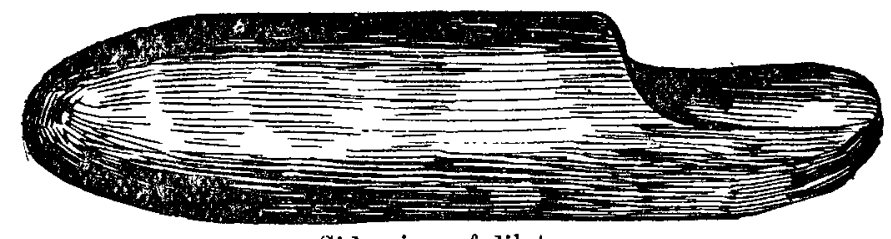

Side view of dilator.

FIG. 2.

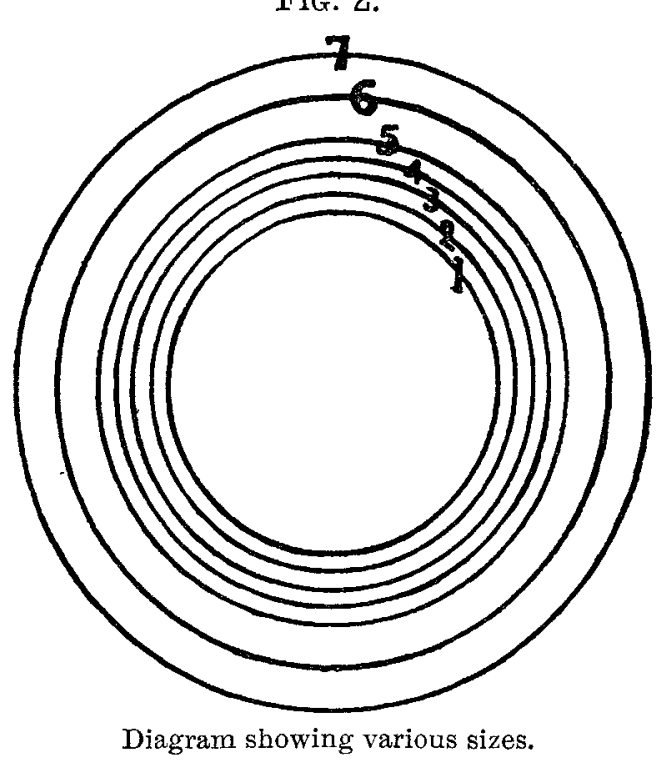

entirely of metal they can be sterilised by boiling. Each dilator is four inches long and, except for the point which is cone-shaped, the sides are parallel. The handle is conveniently shaped to take the ball of the thumb. In using them the smallest size is introduced and allowed to remain till it is no longer nipped but can be withdrawn easily. The next size is then introduced and so on until sufficient dilatation has been obtained. It is possible with this instrument to stretch the sphincters sufficiently to paralyse them without administering an anæsthetic and without hurting the patient. I originally had these dilators made for the purpose of stretching the sphincters in cases of hypertrophy and spasm of these muscles; I have since found them to be of considerable value in a variety of other conditions.

Cavendish-place, $\mathrm{W}$

$$
\text { P. LOCKHART Mummery, F.R.C.S. Eng. }
$$

\section{A NEW FORM OF VAGINAL ELECTRODE.}

HAVING observed that sinusoidal currents when applied by electrodes in the form of a brush produced well-marked irritation of the skin, hyperæmia, and cutis anserina in cases in which electricity conveyed by the usual electrodes did not give rise to any phenomena either subjective or objective, it Bologna 1 to 530, in Pisa 1 to 530, in Naples 1 to 460, and in Pavia 1 to 330 . In towns where there is no university occurred to me that this property of exercising an intensive irritant action might be useful in the treatment of disease when it was desirable to increase the blood-supply of the uterus and adnexa. In my first attempts an electrode in the form of a brush was introduced into the vagina through a speculum, but the process was tedious and not always practicable. I therefore devised an instrument in which an electrode and a speculum are combined. As shown in the illustration, the speculum is in this arrangement represented by a cylindrical vulcanite tube of the requisite length provided with a straight handle. The portion of the tube, $a \mathrm{~B}$,

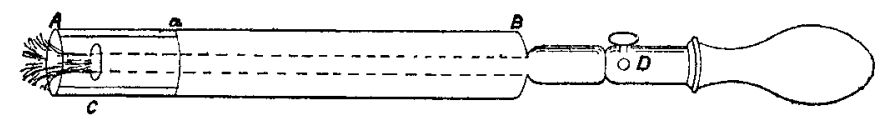

next the handle for about three-fourths of its length has a central perforation for conveying a copper wire, whilst the distal extremity, A $a$, is hollowed out into a wide recess in which a kind of piston carrying a brush can be moved to and fro for a short distance (limited by the nut $\mathbf{C}$ ), so that the brush may at will be either fully drawn into the recess or may project at the end. During the introduction of the tube into the vagina the brush is within the recess until the desired part is reached ; the tube is then drawn back, leaving. the brush exposed and the current is turned on, the conducting wire being clamped by the binding screw $D$. When sinusoidal currents were employed in this way their power of attracting blood was quite perceptible but the results of the physiological observations must remain for future consideration.

Gynæcological Institute, Moscow. $\quad$ Dr. G. SNEGUIREFF.

\section{THE SOCIAL AND ECONOMIC POSITION OF MEDICAL PRACTICE ON THE CONTINENT.}

\section{ITALY.}

A FEW months ago ${ }^{1}$ we gave our readers the result of inquiries addressed to friends in various continental countries with a view of eliciting trustworthy information regarding the various aspects of medical practice and the conditions under which it is carried on amongst those nations. The facts so obtained showed that the grievances complained of in our own country exist in an equal or an aggravated degree in France, Germany, and Austria, and it will be seen from the following account that the condition of the profession in Italy is no better. On account of the extraordinary cheapness of medical education in the latter country the proportion of students recruited from the poorer classes of the population is very large. The fees, taxes, and so on, for the whole six years curriculum do not amount to $£ 40$, including the cost of the diploma, whilst the expense of living in the university towns can be reduced to a very modest figure indeed. The ambition to belong to a learned profession and the opportunity thus afforded on such easy terms of rising in the social scale attract many to the study of medicine who in Great Britain would naturally gravitate into other and humbler walks of life. This tendency is the more marked because of the comparatively low industrial development to which the country has as yet attained and is noticeable in regard to the legal even more than the medical profession. Young men who in other circumstances would become bookkeepers or shop assistants or enter in some other capacity into industrial or commercial life are thus drafted into the medical profession in overwhelming numbers. The total number of medical men in Italy at the last census (February, 1901) was 22,168, or 1 for every 1460 inhabitants, but these figures do not give a just idea of the overcrowding of the profession in the kingdom, since the proportion in the villages is much less, every town or village of less than 10,000 inhabitants having the services of the medici condotti who are disseminated all over the country in a proportion of about 1 for every 2500 or 3000 inhabitants. In the large towns, particularly where a university exists, the ratio is much greater ; for instance, in Catania it is 1 to 800 , in Palermo 1 to 790 , in Turin 1 to 610 , in Genoa 1 to 600 , in Padua 1 to 560, in Rome 1 to 550. in Florence 1 to 550, in the ratio is usually less, being in Milan 1 to 840 , in Venice 1 to 900, in Verona 1 to 1020 , in Bari 1 to 1040 , in Leghorn 1 to 1200 , in Lucca 1 to 1470 , in Trajiani 1 to 1570, in Alessandria 1 to 1650, and in Ravenna 1 to 2000. It will thus be seen that another factor conducing to the overcrowding of the profession is 